\title{
Hybrid repair of aberrant right subclavian artery with aortic dissection caused by Kommerell diverticulum
}

Tieyan $\mathrm{Li}^{1,3+}$, Lin Zou ${ }^{2+}$, Yunzhen Feng ${ }^{1}$, Guoliang Fan ${ }^{1}$ and Yuanfeng Xin ${ }^{1 *}$ (])

\begin{abstract}
Background: Aberrant right subclavian artery (ARSA) with associated Kommerell diverticulum (KD) is a rare congenital aortic disease. KD patients have a high risk of rupture, dissection, and compression of adjacent structures. Although several treatment options have been proposed (traditional surgery, hybrid operation, and endovascular intervention), a consensus regarding optimal surgical management has not yet been established.
\end{abstract}

Case presentation: A case of successful hybrid repair of distal aortic arch dissection aneurysm by dissecting KD and ARSA with debranching of right and left common carotid arteries, left subclavian artery, and stent grafting was presented.

Conclusions: The hybrid operation is suitable for elderly patients or those with high risks. Along with intervention, the hybrid operation needs to be developed as a minimally invasive method.

Keywords: Hybrid repair, Kommerell diverticulum, Aortic dissection

\section{Background}

Kommerell diverticulum (KD) is a rare vascular malformation. When the right subclavian artery appears, the fourth arterial arch is enlarged during embryonic development. The incidence of the right subclavian artery accompanied by the left arterial arch is $0.5-2.0 \%$, while that by the right arterial arch is $0.05 \%$ [1]. The aortic dissection (AD) and rupture are attributed to the abnormal KD tissue. The treatment methods of the aortic dissection caused by KD include traditional surgery, intervention, and hybrid surgery. Herein, we summarized a case report of hybrid surgery and a 6-month postoperative follow-up on the treatment of KD-induced AD.

\section{Case presentation \\ Case}

A 39-year-old male patient presented hypertension and was admitted to the Emergency Department with back pain for $5 \mathrm{~h}$ but without abdominal pain. The blood pressure was $189 / 120 \mathrm{mmHg}$, and the heart rate was $120-150$ beats/min (bpm) at the time if admission. The computed tomography angiography (CTA) showed $\mathrm{AD}$ (type $\mathrm{B}$ ) at the origin of KD (Fig. 1), and the original arterial supplied blood to the superior mesenteric artery and renal artery. The celiac artery was fed by AD. The Emergency Department doctor administered beta-blocker, morphine, and sodium nitroprusside. Then, the patient was transferred to the Cardiac Surgery Department.

\section{Operation}

†Tieyan Li and Lin Zou have contributed equally to this work
†T

${ }^{1}$ Department of Cardiovascular Surgery, Shanghai East Hospital, Tongji

University School of Medicine, Shanghai 200120, People's Republic

of China

Full list of author information is available at the end of the article
The right femoral artery was separated and backed up for cardiopulmonary bypass $(\mathrm{CPB})$ during the operation. The right and left common carotid arteries and the left subclavian artery was dissected through the median 


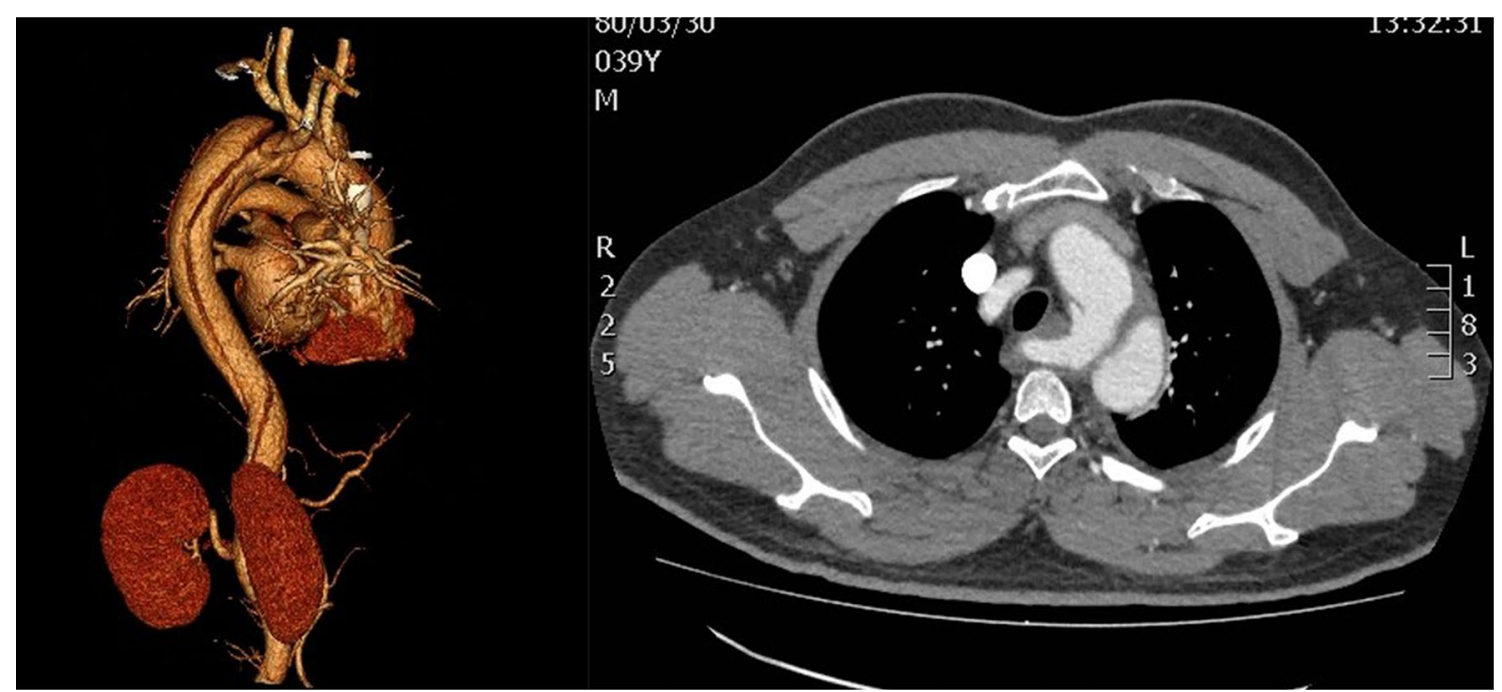

Fig. 1 Before the operation

incision. The ascending aorta was blocked partially by an occlusion aortic clamp. Then, a $26-\mathrm{mm}$ vascular prosthesis with two $8-\mathrm{mm}$ branches was sutured to the side of the artery using 4-0 prolene. One branch of the artificial vessel was connected to the right common carotid artery, while the other was sutured to the left subclavian artery end-to-end and to the left common carotid artery side-to-end. Subsequently, the intervention was conducted by puncturing a $6 \mathrm{~F}$ sheath into the right femoral artery using Seldinger's method. A supersmooth guidewire was placed into the abdominal aorta through the sheath. The pigtail catheter was inserted into the artery along the guidewire. The radiography image ensured that the catheter was in the true lumen. Then, the catheter with the guidewire was delivered to the ascending aorta. The radiography captured images under the following parameters: left anterior oblique $65^{\circ}$, contrast agent volume $20 \mathrm{~mL}$, flow speed $25 \mathrm{~mL} / \mathrm{s}$, and pressure $400 \mathrm{~Pa}$ to measure the dissection position and the starting point of KD. Subsequently, two aortic stents were released (Fig. 2). The first one had 38-32 $\mathrm{mm}$ width and $160 \mathrm{~mm}$ length fixed next to the anastomosis of the thoracic artery and artificial vessel. The second stent was $36-30 \mathrm{~mm}$ wide and $160 \mathrm{~mm}$ long and fixed partially inside the first one that covered the AD. The final radiography image showed a well-shaped stent without any leak between the stents and vessel (Fig. 3). Next, we used 5-0 prolene to suture the femoral artery. The blood pressure was measured in the femoral and dorsal foot arteries. The pressure of the left and radial arteries was $134 / 76$ and $117 / 56 \mathrm{mmHg}$, respectively. Since the difference in the pressure between the left and right artery was $<40 \mathrm{mmHg}$, and hence, the reconstruction of the right Kommerell artery was rejected.

\section{Results}

The total operation time was $4 \mathrm{~h}$ without CPB. The intubation of the patient was removed after $7 \mathrm{~h}$, but he stayed in the intensive care unit (ICU) for 1 day. The whole therapy process did not involve any blood transfusion. Before discharge, the CTA of the patient showed an open aortic lumen, and the thoracic aortic false cavity was closed, while the right subclavian artery was $8 \mathrm{~mm}$ wide (Fig. 4). The abdominal aorta presented AD. However, after 6 months, the abdominal aortic false cavity closed, and the KD disappeared (Fig. 5). The follow-up revealed that all the thoracic and abdominal arterial branches are supplied blood from the true lumen. The difference in the pressure between the two upper limbs was $<10 \mathrm{mmHg}$.

\section{Discussion and conclusions}

Typically, KD is in a deep position and diagnosed when the diverticulum presses the esophagus or trachea. Previous studies have shown that the incidence of $A D$ in the KD patient is $40-53 \%$, which is higher than that in normal individuals [2]. Based on the site of hemodynamics, the artery receives shear stress, which eases the AD [3]. From a pathological perspective, medial cystic necrosis is common in KD patients, especially in those with atherosclerosis. The weak vascular tissue regresses to the aneurysm, even to $\mathrm{AD}$ [4]. The aortic breakage of KD patients often appears near the breach of the diverticulum. Because of the long distance between the breakage and the ascending artery, the artery tears in reverse to the aortic arch. This phenomenon also explains the 


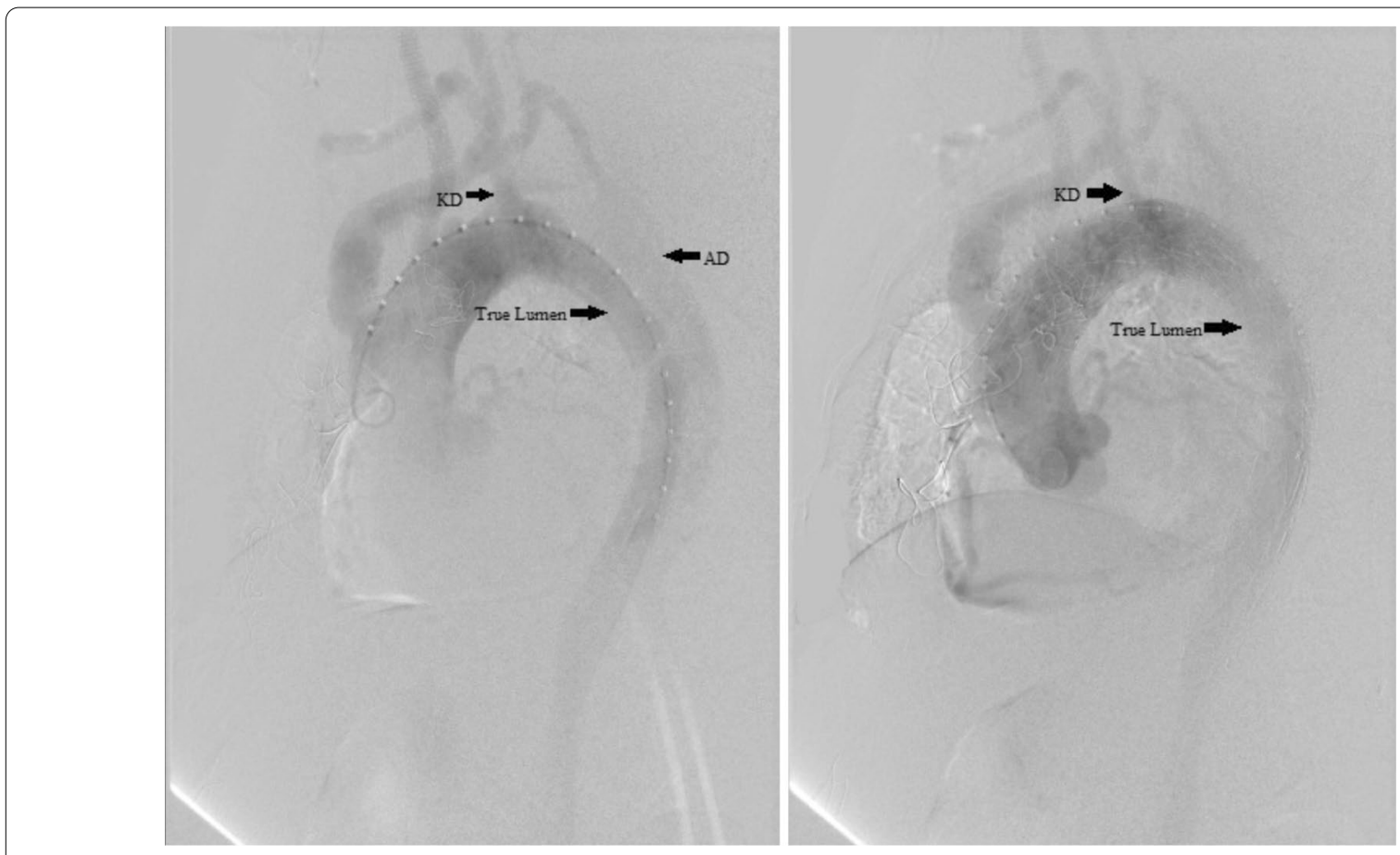

Fig. 2 Radiography images during the operation

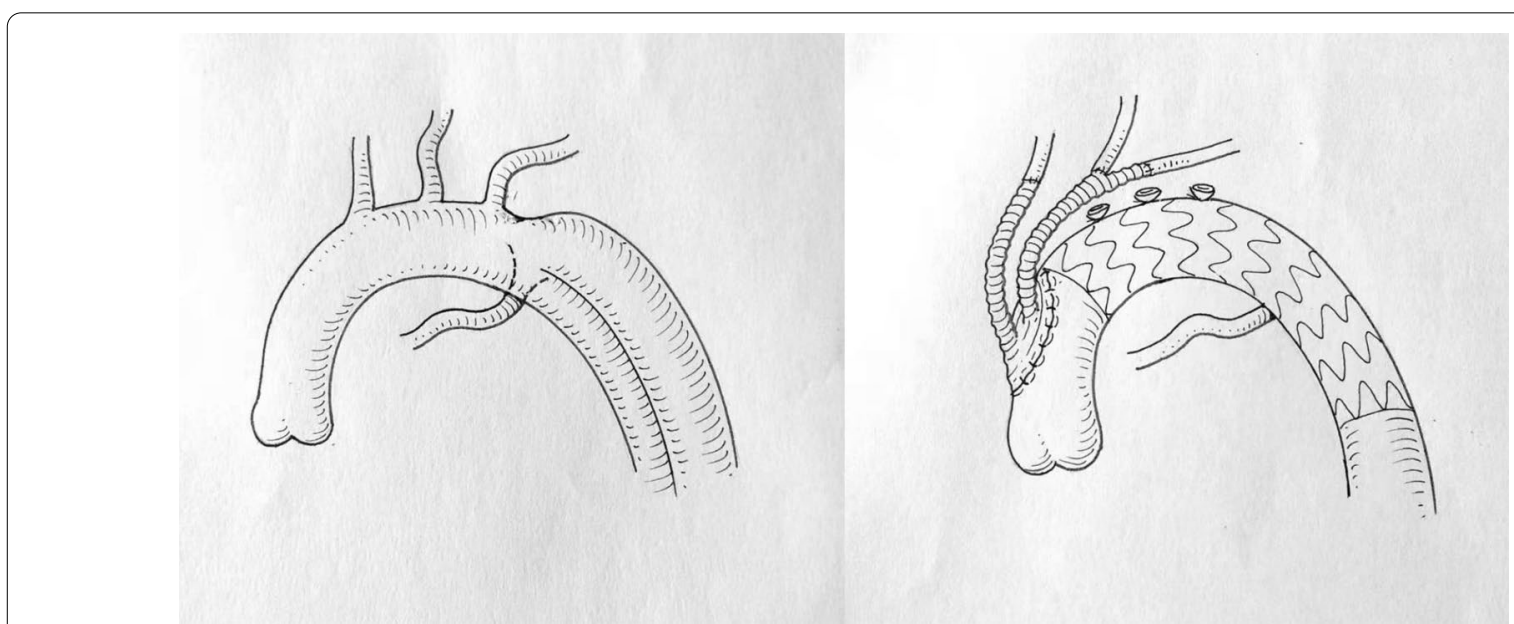

Fig. 3 Schematic illustration of the anatomy and the operation. (Our own hand-drawn draft)

frequency of Type B than Type A AD. In this case report, the patient presented hypertension history, and hence, the blood pressure was not controlled adequately.

The surgical indication of KD is controversial. Backer et al. suggested that the operation should be conducted when the diameter of the diverticulum is 1.5 -fold that of the subclavian artery [5]. Ota et al. proposed that the surgical indication should be considered when the diameter of $\mathrm{KD}$ is $>5 \mathrm{~cm}$, and the diverticulum suppresses the mediastinum [6]. According to Cina et al., the difficulty of the surgery depends on the diameter of KD. Thus, intervention is essential when the diameter of the diverticulum is $>3 \mathrm{~cm}$ [7].

Furthermore, the surgical indication is definite when $\mathrm{KD}$ leads to $\mathrm{AD}$. The operation methods include the traditional surgical operation, thoracic endovascular aortic repair (TEVAR), and hybrid operation. Currently, there is a lack of unified opinion on the operation methods, 


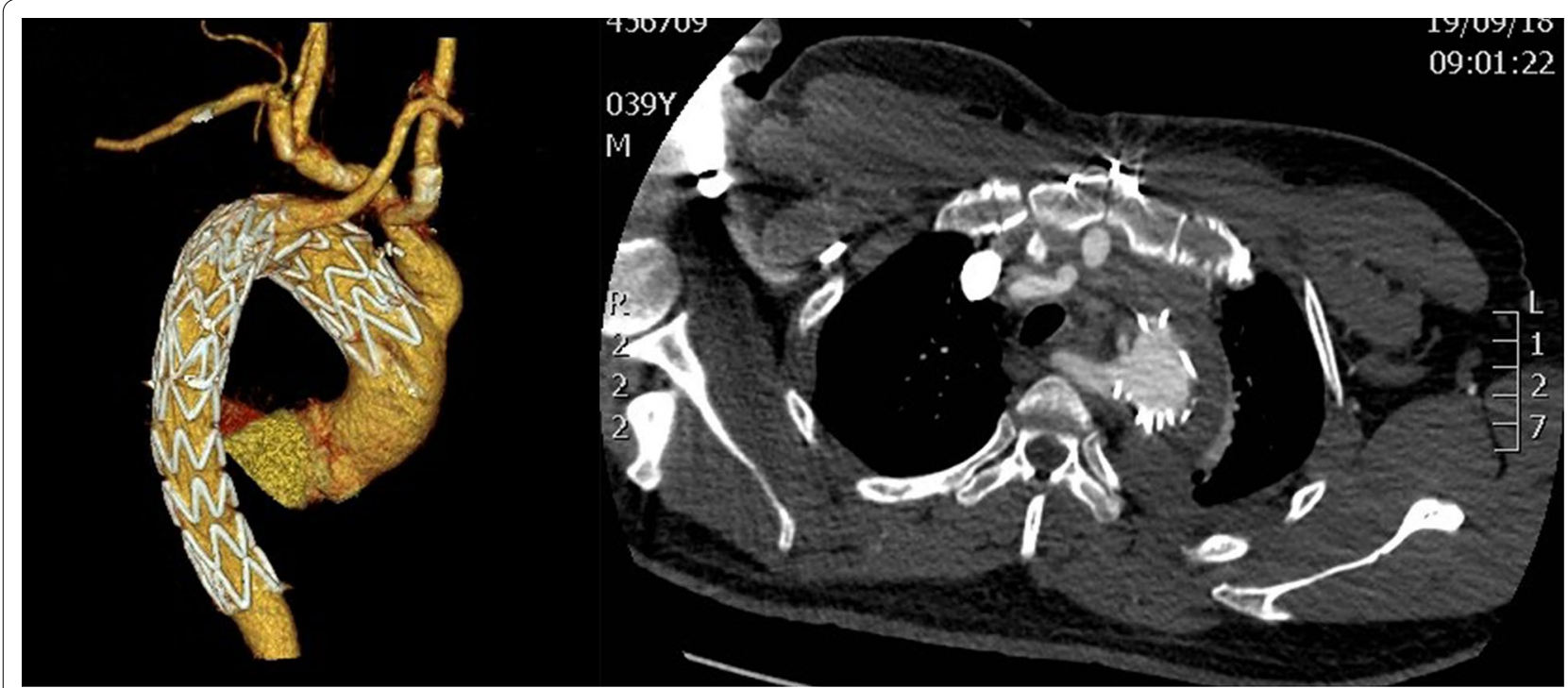

Fig. 4 Before discharge from the hospital

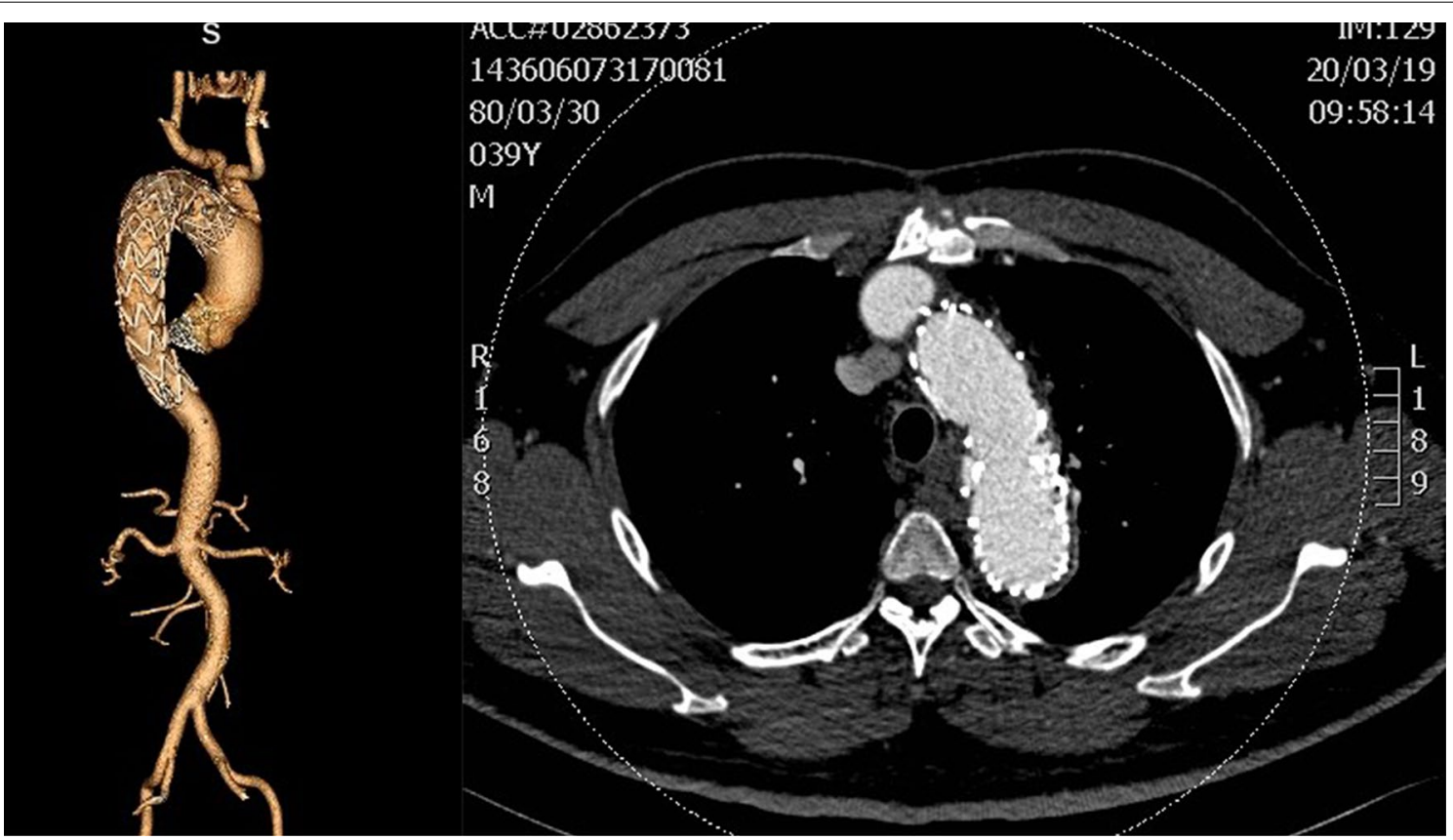

Fig. 5 6-month follow-up results

especially for type $\mathrm{B} A \mathrm{AD}$ caused by $\mathrm{KD}$. If the range of the AD is limited, traditional surgery can be considered. Since the median incision does not provide adequate exposure, the lateral thoracic incision is also needed. The bigger the injury and the deeper the hypothermia, the perioperative mortality and the complication reaches up to $15 \%$ [8]. Along with the development of the intervention, TEVAR is a minimally invasive treatment.
However, it may cause severe complications because the main branches of the artery are isolated. Although the tailored aortic stent can reduce complications, it is not suitable for emergency operations. The chimney aortic stent is another method, but the endoleak of the stent is about $22 \%$ due to the poor compliance of the chimney [9]. Thus, it could be deemed that TEVAR is suitable for elderly patients or those intolerable to a surgery. 
The hybrid operation consists of the surgical method and TEVAR, which comprises a safe treatment for KD patients with Type B AD. Previous studies have shown that the $\mathrm{Z} 2$ zone is the ideal anchor for the aortic stent, while some studies indicate the $\mathrm{Z0}$ as the safe zone [10]. If the aortic atherosclerosis is severe or the aortic calcification is extensive, especially along the aortic arch, the ideal anchor for the aortic stent should be the Z2 or Z3 zone; otherwise, the $\mathrm{Z0}$ zone may be the ideal anchor that shapes the aortic lumen adequately. Herein, we chose the $\mathrm{Z} 0$ zone as the anchor in this case. Therefore, the aortic stent had sufficient support area in the artery [11]. The second stent overlapped the first and encompassed that branch of KD. The whole operation process was monitored by transesophageal echocardiography (TOE) that can help the surgeon check the cardiac function and the position of AD. The 6-month follow-up after the operation revealed that the false aortic cavity is closed. The main branches of the abdominal artery are supplied blood via the true artery. Next, we used the debranch of the artificial vessel to rebuild the three main branches of the aortic arch. Thus, it could be stated that the advantage of hybrid operation is minimal injury. The connection between the ascending artery and the artificial vessel is implied without CPB. However, the operation does not require deep hypothermia. Surgical hemostasis is much easier than the traditional aortic operation. The surgery provides an anchor zone that can reduce the incidence of type I endoleak. The debranch of the artificial vessel ensures sufficient blood supply to the brain and limbs. The 6-month outpatient follow-up results did not show any significant difference between the pressures of the upper limbs.

Taken together, KD coincided with aortic dissection is a rare disease. The hybrid operation is suitable for elderly patients or those with high risks. Along with intervention, the hybrid operation needs to be developed as a minimally invasive method.

\section{Abbreviations \\ CPB: Cardiopulmonary bypass; CTA: Computed tomography angiography; ICU: Intensive care unit; KD: Kommerell diverticulum; TEVAR: Thoracic endovascular aortic repair. \\ Acknowledgements \\ None. \\ Authors' contributions \\ (I) Conception and design: TYL, LZ, and YFX, (II) administrative support: $L Z$ and YFX, (III) substantive revision: YZF and GLF, (IV) collection and assembly of data: TYL and YZF, (V) data analysis and interpretation: TYL and LZ, (VI) manuscript writing: all authors, (VII) final approval of manuscript: all authors. All authors read and approved the final manuscript.}

\section{Funding}

This study was supported by the Young Medical Talents Training Program of Pudong Health Bureau of Shanghai (Grant No. PWRq2020-30), The
National Key R\&D Program of China (2017YFA0105600), and Major Program of Development Fund for Shanghai Zhangjiang National Innovation Demonstration Zone (ZJ2018-ZD-004). The funders had no role in the study design, data collection and analysis, decision to publish, or preparation of the manuscript.

\section{Availability of data and materials}

The dataset supporting the results of this study is included in the article.

\section{Declarations}

Ethics approval and consent to participate

Standard care is given, and hence, ethical approval is not applicable in this study. Written informed consent was obtained from the patient.

\section{Consent for publication}

Written informed consent was obtained from the patient.

\section{Competing interests}

The authors declare that they have no competing interests.

\section{Author details}

${ }^{1}$ Department of Cardiovascular Surgery, Shanghai East Hospital, Tongji University School of Medicine, Shanghai 200120, People's Republic of China. ${ }^{2}$ Department of Endocrinology, Shanghai Pudong New Area Gongli Hospital, Shanghai 200135, People's Republic of China. ${ }^{3}$ Shanghai Engineering Research Center of Artificial Heart and Heart Failure Medicine, Shanghai 200120, People's Republic of China.

Received: 21 June 2021 Accepted: 22 October 2021

Published online: 22 November 2021

\section{References}

1. Yang C, Shu C, Li M, Li Q, Kopp R. Aberrant subclavian artery pathologies and Kommerell's diverticulum: a review and analysis of published endovascular/hybrid treatment options. J Endovasc Therapy. 2012;19(3):373-82.

2. Tanaka A, Milner R, Ota T. Kommerell's diverticulum in the current era: a comprehensive review. General Thoracic Cardiovasc Surg. 2015;63(5):245-59.

3. Rosu C, Dorval JF, Abraham CZ, Cartier R, Demers P. Single-stage hybrid repair of right aortic arch with Kommerell's diverticulum. Ann Thoracic Surg. 2017;103(4):e381-4.

4. Ramaswamy P, Lytrivi ID, Thanjan MT, Nguyen T, Srivastava S, Sharma S, Ko HH, Parness IA, Lai WW. Frequency of aberrant subclavian artery, arch laterality, and associated intracardiac anomalies detected by echocardiography. Am J Cardiol. 2008;101(5):677-82.

5. Backer CL, Russell HM, Wurlitzer KC, Rastatter JC, Rigsby CK. Primary resection of Kommerell diverticulum and left subclavian artery transfer. Ann Thoracic Surg. 2012;94(5):1612-7.

6. Ota T, Okada K, Takanashi S, Yamamoto S, Okita Y. Surgical treatment for Kommerell's diverticulum. J Thoracic Cardiovasc Surg. 2006:131(3):574-8.

7. Cinà CS, Althani H, Pasenau J, Abouzahr L. Kommerell's diverticulum and right-sided aortic arch: a cohort study and review of the literature. J Vasc Surg. 2004;39(1):131-9.

8. Myers PO, Fasel JH, Kalangos A, Gailloud P. Arteria lusoria: developmental anatomy, clinical, radiological and surgical aspects. Annales de cardiologie et d'angeiologie. 2010;59(3):147-54.

9. van Bogerijen GH, Patel HJ, Eliason JL, Criado E, Williams DM, Knepper J, Yang B, Deeb GM. Evolution in the management of aberrant subclavian arteries and related Kommerell diverticulum. Ann Thoracic Surg. 2015;100(1):47-53.

10. Idrees J, Keshavamurthy S, Subramanian S, Clair DG, Svensson LG, Roselli EE. Hybrid repair of Kommerell diverticulum. J Thoracic Cardiovasc Surg. 2014;147(3):973-6. 
11. Kim KM, Cambria RP, Isselbacher EM, Baker JN, LaMuraglia GM, Stone JR, MacGillivray TE. Contemporary surgical approaches and outcomes in adults with Kommerell diverticulum. Ann Thoracic Surg. 2014;98(4):1347-54.

\section{Publisher's Note}

Springer Nature remains neutral with regard to jurisdictional claims in published maps and institutional affiliations.
Ready to submit your research? Choose BMC and benefit from:

- fast, convenient online submission

- thorough peer review by experienced researchers in your field

- rapid publication on acceptance

- support for research data, including large and complex data types

- gold Open Access which fosters wider collaboration and increased citations

- maximum visibility for your research: over $100 \mathrm{M}$ website views per year

At BMC, research is always in progress.

Learn more biomedcentral.com/submissions 